\title{
Health Profile of Australian Adolescents with Intellectual Disability
}

\author{
Tran Tuan Anh Le ${ }^{1,2, *(\mathbb{D}}$, Robert S. Ware ${ }^{1,3}{ }^{\mathbb{D}}$, Simon Denny ${ }^{4}$, Nicholas Lennox ${ }^{1}$, Lyn McPherson ${ }^{1,3} \mathbb{D}$ \\ and David Harley ${ }^{5}$ (D)
}

1 Queensland Centre for Intellectual and Developmental Disability, Mater Research Institute-UQ, The University of Queensland, Brisbane, QLD 4101, Australia; r.ware@griffith.edu.au (R.S.W.); n.lennox@uq.edu.au (N.L.); lyn.mcpherson@griffith.edu.au (L.M.)

2 Department of Psychiatry, Hue University of Medicine and Pharmacy, Hue University, Hue V-49000, Vietnam 3 Menzies Health Institute Queensland, Griffith University, Brisbane, QLD 4111, Australia

4 Mater Young Adult Health Centre, Mater Health, Brisbane, QLD 4101, Australia; Simon.Denny@mater.org.au 5 Centre for Clinical Research, University of Queensland, Brisbane, QLD 4029, Australia; d.harley@uq.edu.au

* Correspondence: a.t.le@uq.net.au or letrantuananh@hueuni.edu.vn or lttanh@huemed-univ.edu.vn; Tel.: +84-983-060-393 or +61-434-529-443

Citation: Le, T.T.A.; Ware, R.S.; Denny, S.; Lennox, N.; McPherson, L.; Harley, D. Health Profile of Australian Adolescents with Intellectual Disability. Disabilities 2021, 1, 377-387. https://doi.org/ 10.3390/disabilities1040026

Academic Editors: Janet Finlayson and Stuart Todd

Received: 23 August 2021

Accepted: 13 October 2021

Published: 19 October 2021

Publisher's Note: MDPI stays neutral with regard to jurisdictional claims in published maps and institutional affiliations.

Copyright: (c) 2021 by the authors. Licensee MDPI, Basel, Switzerland. This article is an open access article distributed under the terms and conditions of the Creative Commons Attribution (CC BY) license (https:/ / creativecommons.org/licenses/by/ $4.0 /)$.

\begin{abstract}
Background: Data on the health of adolescents with intellectual disability are scarce. This study describes carer-reported symptoms, chronic illnesses, level of functioning, and behaviour among Australian adolescents with intellectual disability. We compare students attending mainstream and special schools. Methods: Cross-sectional questionnaire data were obtained from a cohort of 592 adolescents (10-21 years) with intellectual disability attending school and living in South-East Queensland, Australia, in May 2007. We analysed data from a subset (176) who completed a health check before visiting their general practitioners. Results: Adolescents had significant health needs, and those in special education schools had worse health than those from mainstream schools. There was a discrepancy between the prevalence of significant psychopathology detected via the short form Developmental Behaviour Checklist (DBC-P24) and psychiatric conditions reported by carers. Conclusions: Given the significant health needs of this population, carefully designed and targeted programs, potentially including medical visits to these schools, are needed.
\end{abstract}

Keywords: intellectual disability; adolescents; health; behaviour; functioning; symptoms

\section{Introduction}

One percent of the world's population has an intellectual disability [1]. In recent decades, there has been significant development in terms of health and welfare services for people with intellectual disability. Despite this, people with intellectual disability continue to have poorer health than their non-disabled peers [2,3]. Studies on adolescents with intellectual disability have reported the prevalence of having one or more carer-reported chronic disease to be $40-60 \%$ [4,5], and carer-reported chronic mental condition to be 18-23\% [4,6]. Attention-deficit/hyperactivity disorder (ADHD), dyslexia, autism spectrum disorder (ASD), and pervasive developmental disorder not otherwise specified occurred at a prevalence $21,14,11$, and $14 \%$, respectively, among 1083 adolescents with intellectual disability [4].

There are deficiencies in the capacity of health services to care for people with intellectual disability, especially during the transition between adolescence and adulthood [7]. This transition creates additional stressors because young people, including many with intellectual disability, are seeking independence, wanting to explore intimate relationships, and move out from family homes [8]. Specific health and developmental services are needed at this life stage but are often lacking [7].

The majority of adolescents with intellectual disability also have difficulty with everyday life activities. Westwood [9] found that over $90 \%$ of adolescents with intellectual 
disability attending special schools have limited ability with practical (independent eating, dressing, mobility, and toileting) and conceptual (communication, functional academics, and self-direction) skills. Similarly, Young-Southward, Rydzewska, Philo, and Cooper [5] found that about $90 \%$ of adolescents with intellectual disability had their day-to-day activities limited.

Challenging behaviours in this population are widespread, being reported in $30 \%$ to $47 \%$ of adolescents with intellectual disability living in the community [10,11], and $53 \%$ of adolescents with intellectual disability attending special schools [12]. These behaviours include self-injury (36\%), aggressive-destructive behaviour (30\%), and stereotyped behaviour $(26 \%)$ [12]. Adolescents with intellectual disability are often prescribed psychotropic medication, often off-label or inappropriately, for behaviour problems $[13,14]$.

Little is known about the health status of Australian adolescents with intellectual disability. Detailed data, such as on the prevalence of symptoms, dental, vision, and hearing problems among adolescents with intellectual disability are lacking. Data on the health of adolescents with intellectual disability are crucial for more effective and targeted health promotion and disease prevention by governments, health professionals, and schools. Policymakers need these data for the better planning of health care services [4]. Health professionals need these data for early detection and timely treatment [4]. Teachers need these data to inform the development of health programs to address unmet health needs and prevent disease and injury.

Children and adolescents with intellectual disability are generally streamed to either special schools catering exclusively for students with intellectual disability or to mainstream schools, where students with intellectual disability are in general or special classes depending on the level of support needed. Adolescents with intellectual disability from special schools generally have greater health needs compared with those attending mainstream schools. The aim of this study was to describe carer-reported symptoms, chronic illness, level of functioning, and behavioural issues of Australian adolescents with intellectual disability, and to compare characteristics according to the type of school attended.

\section{Methods}

\subsection{Study Population}

Cross-sectional questionnaire data were collected from carers of adolescents with intellectual disability who lived in the community and attended high school in South-East Queensland, Australia. Data were collected as part of a randomised controlled trial, the Ask study, which evaluated the effectiveness of a health intervention package on the longterm health of adolescents with intellectual disability [15]. The trial was conducted from February 2007 to June 2010. Full details of the trial are in the study protocol [15] and the two main outcome papers [16,17]. Data on demographic, social and clinical characteristics, level of functioning, and behaviour problems were collected through baseline questionnaires before receipt of the health-intervention package.

Children and young people aged from 10 to 21 years (on 1 July 2007) with an Education Queensland-verified intellectual disability attending a special education unit (SEU) or a special education school (SES) in South-East Queensland were eligible. Having an Education Queensland-verified intellectual disability required evidence of impairment from a guidance officer or psychologist. At that time, SEUs were situated within conventional elementary or secondary school campuses. An SES was a separate special school for children and young people with significant intellectual disability. Participants attending an SEU were usually less severely disabled than SES students, with access to the conventional curriculum, as well as to specialist therapy and teaching services. Participants attending SESs had more severe intellectual disability or multiple disabilities and typically needed specialised education and therapy services that facilitated a personalised education programme. 


\subsection{Data Collection}

Consent was obtained from the principals or heads of schools, teachers, carers, and nominated general practitioners (GPs). Subsequently, participants were allocated into the control group or the intervention group. Control group participants received their usual medical care and education. Intervention group participants received the health intervention package, which consisted of a hand-held health record with health advocacy tips (Ask Health Diary) and a health check (Comprehensive Health Assessment Program-CHAP) [15].

\subsection{Baseline Questionnaire}

Data on demographic, social and clinical characteristics, school type, level of functioning, and behaviour problems were obtained from carers of all study participants via baseline questionnaires mailed in May 2007. The baseline questionnaire was developed by a working party consisting of a teacher, a paediatrician, a general practitioner with many years' experience in intellectual disability, and an epidemiologist and statistician to offer advice in questionnaire development as required. Social characteristics included socio-economic status ranked at the postcode level using the Australian Bureau of Statistics Socio-Economic Index for Areas 2006, a measure of relative disadvantage [18], and the carer's highest level of education. Clinical characteristics included the aetiology of intellectual disability, general health status, and known health conditions. Carers were asked to provide data on specific health conditions for the adolescent they cared for. The questionnaire also allowed carers to provide information on health conditions that were not listed.

Level of functioning for communication ability, mobility, grooming and personal care, feeding and drinking, toilet use, dressing, walking upstairs, showering, or bathing was recorded. These questions were based on items from the Barthel Index for Activities of Daily Living [19], except for the question about communication ability, which was developed by the research team. Psychopathology was measured using the short form of the Developmental Behaviour Checklist (DBC-P24), which is the short form of the Developmental Behaviour Checklist-Parent version (DBC-P) [20]. DBC-P has excellent sensitivity and specificity in detecting psychiatric caseness [21]. The DBC-P24 consists of 24 items, with each item based on participant behaviour in the past six months and scored on a three-level scale as 0: not true; 1: somewhat or sometimes true; and 2: very true or often true [20]. The participant is defined as having significant psychopathology if the Mean Behaviour Problem Score (MPBS) from DBC-P24 is 0.48 or greater [20].

\subsection{Health Check Booklets}

CHAP booklets were sent to participants allocated to receive the intervention in November 2007. The booklets were based on the versions used in previous adult studies [22,23] and tested in a pilot study before this randomised controlled trial [24]. Although the CHAP has not been tested for validity and reliability, it is one of few health assessment tools that has had been subject to effectiveness trials [25].

The booklet consists of two parts. Carers, in some cases with contributions from adolescents, completed their sections of the health check before booking an appointment to visit their GPs. The first part of the booklet listed typical symptoms experienced by the adolescents with intellectual disability including symptoms related to respiratory, cardiovascular, musculoskeletal, gastrointestinal, urinary, nervous, and skin systems. Carers reported whether the adolescent had any of those symptoms in the past year, as well as vision and hearing problems. Answers were yes, no, and unsure. The second part of the CHAP booklet was completed by the GP and included information on dental diseases and other findings from a physical examination. Participants were asked to return their health check booklets to the study team after their GP appointments. Information on symptoms experienced during the last year, vision and hearing problems, and dental pathology were derived from these booklets. 


\subsection{Statistical Analysis}

Summary statistics are reported as frequency (percentage). For symptoms, vision, and hearing problems, responses of "unsure" were removed from analyses. Associations between school type and reported health outcomes (excluding mean scores of behaviour problems in the DBC-P24) were calculated using a generalised linear model with a binomial family and an identity link, with effect estimates presented as risk difference $(95 \%$ confidence interval; CI). Associations between school type and mean scores of behaviour problems in the DBC-P24 were calculated using a linear regression model with robust standard errors, with effect estimates presented as mean difference (95\% CI). Robust standard errors (clustered on individual schools) were used to account for the sampling scheme. Analyses were conducted using Stata v16 (StataCorp LLC, College Station, TX, USA).

\subsection{Ethics}

Ethics approval was granted by the Queensland Government Department of Education and the Arts (File No: 550/27/424) and the University of Queensland Behavioural and Social Sciences Ethical Review Committee (Clearance No: 2004000081).

\section{Results}

From an initial 160 eligible SESs and SEUs, 75 were excluded because they had fewer than 10 enrolments $(n=49)$, were enrolled in the pilot project $(n=1)$, had transient student populations $(n=6)$, were at a distant location $(n=3)$, or declined to participate $(n=$ 16) [15]. Of the 423 participants allocated to the intervention arm and 304 to the control arm, 592 completed baseline questionnaires and 176 from the intervention group returned their completed health check booklets. For participants with completed baseline questionnaires, $324(54.7 \%)$ were male, $320(54.1 \%)$ were from an SES, and $76(12.8 \%)$ had Down syndrome (Table 1). Participant ages ranged from 10 to 19 years, other than one participant aged 21 years. Characteristics of the 176 participants who completed CHAP health checks are displayed in Table S1.

Table 1. Demographic, social, and clinical characteristics of participants in the Ask study who completed baseline questionnaires $(n=592)$.

\begin{tabular}{|c|c|c|c|}
\hline Characteristic & $\begin{array}{c}\text { Total }(n=592) \\
n(\%)\end{array}$ & $\begin{array}{c}\text { Special Education } \\
\text { School }(n=320) \\
n(\%)\end{array}$ & $\begin{array}{l}\text { Special Education Unit } \\
\qquad(n=272) \\
n(\%)\end{array}$ \\
\hline \multicolumn{4}{|l|}{ Age (years) } \\
\hline $10-13$ & $103(17.4 \%)$ & $73(22.8 \%)$ & $30(11.0 \%)$ \\
\hline $14-16$ & $366(61.8 \%)$ & $178(55.6 \%)$ & $188(69.1 \%)$ \\
\hline $17-21$ & $123(20.8 \%)$ & $69(21.6 \%)$ & $54(19.9 \%)$ \\
\hline \multicolumn{4}{|l|}{ Gender } \\
\hline Male & $324(54.7 \%)$ & $197(61.6 \%)$ & $127(46.7 \%)$ \\
\hline \multicolumn{4}{|l|}{ Aetiology of Intellectual Disability } \\
\hline Down syndrome & $76(12.8 \%)$ & $62(19.4 \%)$ & $14(5.1 \%)$ \\
\hline Other known cause & $332(56.1 \%)$ & $183(57.2 \%)$ & $149(54.8 \%)$ \\
\hline Unknown cause & $184(31.1 \%)$ & $75(23.4 \%)$ & $109(40.1 \%)$ \\
\hline \multicolumn{4}{|l|}{ Carer's highest level of education ${ }^{1}$} \\
\hline Post-secondary & $130(22.5 \%)$ & $86(27.7 \%)$ & $44(16.5 \%)$ \\
\hline Others & $447(77.5 \%)$ & $224(72.3 \%)$ & $223(83.5 \%)$ \\
\hline \multicolumn{4}{|l|}{ Location ranked by level of socio-economic advantage } \\
\hline Low & $146(24.7 \%)$ & $65(20.3 \%)$ & $81(29.8 \%)$ \\
\hline Medium & $270(45.6 \%)$ & $137(42.8 \%)$ & $133(48.9 \%)$ \\
\hline High & $176(29.7 \%)$ & $118(36.9 \%)$ & $58(21.3 \%)$ \\
\hline \multicolumn{4}{|l|}{ General health status ranked by carers } \\
\hline Excellent & $165(27.9 \%)$ & $78(24.4 \%)$ & $87(32.0 \%)$ \\
\hline Very good & $191(32.3 \%)$ & $110(34.4 \%)$ & $81(29.8 \%)$ \\
\hline Good & $177(29.9 \%)$ & $91(28.4 \%)$ & $86(31.6 \%)$ \\
\hline Fair & $52(8.8 \%)$ & $34(10.6 \%)$ & $18(6.6 \%)$ \\
\hline Poor & $7(1.2 \%)$ & $7(2.2 \%)$ & $0(0.0 \%)$ \\
\hline \multicolumn{4}{|l|}{ Known health conditions reported by carers ${ }^{2}$} \\
\hline At least one chronic physical or psychiatric condition & $386(65.4 \%)$ & $229(71.6 \%)$ & $157(58.2 \%)$ \\
\hline At least one chronic physical condition & $379(64.2 \%)$ & $225(70.3 \%)$ & $154(57.0 \%)$ \\
\hline Epilepsy & $121(20.6 \%)$ & $93(29.2 \%)$ & $28(10.4 \%)$ \\
\hline
\end{tabular}


Table 1. Cont.

\begin{tabular}{|c|c|c|c|}
\hline Characteristic & $\begin{array}{c}\text { Total }(n=592) \\
n(\%)\end{array}$ & $\begin{array}{c}\text { Special Education } \\
\text { School }(n=320) \\
n(\%)\end{array}$ & $\begin{array}{l}\text { Special Education Unit } \\
\qquad(n=272) \\
n(\%)\end{array}$ \\
\hline Heart condition & $64(10.9 \%)$ & $42(13.1 \%)$ & $22(8.2 \%)$ \\
\hline Psychiatric condition & $39(6.6 \%)$ & $27(8.4 \%)$ & $12(4.4 \%)$ \\
\hline Thyroid problems & $21(3.6 \%)$ & $16(5.0 \%)$ & $5(1.9 \%)$ \\
\hline Reflux oesophagitis & $34(5.8 \%)$ & $24(7.6 \%)$ & $10(3.7 \%)$ \\
\hline Aspiration & $13(2.2 \%)$ & $9(2.8 \%)$ & $4(1.5 \%)$ \\
\hline
\end{tabular}

${ }^{1}$ Missing information for 15 participants, 10 in special education schools and 5 in special education units. ${ }^{2}$ Number of "don't know" responses for known health conditions reported by carers: having at least one chronic physical or psychiatric condition known by carers: 2 (both in special education units), having at least one chronic physical condition known by carers: 2 (both in special education units), epilepsy: 4 (1 in special education schools and 3 in special education units), heart condition: 2 (both in special education units), psychiatric condition: 2 (both in special education units), thyroid problems: 3 (all in special education units), reflux oesophagitis: 4 (2 in special education schools and 2 in special education units), aspiration: 4 (all in special education units).

Most participants had significant impairments in functioning, with $66.7 \%$ needing help with grooming and personal care, $36.3 \%$ needing help with feeding or drinking, and $23.5 \%$ having difficulty with verbal communication. As expected, functional impairments were significantly higher among participants in SESs compared with SEUs located in mainstream schools (Table 2).

Table 2. Level of functioning of participants in the Ask study who completed baseline questionnaires $(n=592)$.

\begin{tabular}{|c|c|c|c|c|}
\hline Level of Functioning & $\begin{array}{c}\text { Total }(n=592) \\
n(\%)\end{array}$ & $\begin{array}{c}\text { Special Education } \\
\text { School }(n=320) \\
n(\%)\end{array}$ & $\begin{array}{c}\text { Special Education } \\
\text { Unit }(n=272) \\
n(\%)\end{array}$ & $\begin{array}{l}\text { Risk Difference } \\
\qquad(95 \% \mathrm{CI})^{1}\end{array}$ \\
\hline Needs help with grooming and personal care & $393(66.7 \%)$ & $275(86.2 \%)$ & $118(43.7 \%)$ & $\begin{array}{c}42.5 \% \\
\text { (34.6\% to } 50.4 \%)\end{array}$ \\
\hline Needs help with dressing & $308(52.1 \%)$ & $244(76.3 \%)$ & $64(23.6 \%)$ & $\begin{array}{c}52.6 \% \\
(46.0 \% \text { to } 59.3 \%)\end{array}$ \\
\hline Needs help with showering or bathing & $287(48.6 \%)$ & $234(73.1 \%)$ & $53(19.6 \%)$ & $\begin{array}{c}53.6 \% \\
(45.8 \% \text { to } 61.3 \%)\end{array}$ \\
\hline Needs help with feeding and drinking & $213(36.3 \%)$ & $180(56.6 \%)$ & $33(12.3 \%)$ & $\begin{array}{c}44.3 \% \\
(37.1 \% \text { to } 51.6 \%)\end{array}$ \\
\hline Needs help with toilet use & $206(35.0 \%)$ & $175(54.9 \%)$ & $31(11.5 \%)$ & $\begin{array}{c}43.3 \% \\
(34.9 \% \text { to } 51.7 \%)\end{array}$ \\
\hline Difficulty in verbal communication ${ }^{2}$ & $138(23.5 \%)$ & $121(38.1 \%)$ & $17(6.3 \%)$ & $\begin{array}{c}31.8 \% \\
(26.4 \% \text { to } 37.1 \%)\end{array}$ \\
\hline Needs help with walking up stairs & $113(19.2 \%)$ & $101(31.7 \%)$ & $12(4.4 \%)$ & $\begin{array}{c}27.2 \% \\
\text { (21.4\% to } 33.0 \%)\end{array}$ \\
\hline Needs help with mobility/wheelchair/immobile & $81(13.7 \%)$ & $69(21.6 \%)$ & $12(4.4 \%)$ & $\begin{array}{c}17.2 \% \\
(11.5 \% \text { to } 22.8 \%)\end{array}$ \\
\hline
\end{tabular}

${ }^{1}$ Risk difference presented as SES relative to SEU [reference]. ${ }^{2}$ Included some verbal communication with nonverbal aids (e.g., gestures, communication boards), mainly nonverbal communication, mainly facilitated communication.

Many participants exhibited signs suggesting psychopathology, with over two-thirds $(67.2 \%)$ classified as having significant psychopathology as assessed by the DBC-P24. This was higher (74.5\%) among participants from SESs than SEUs (58.5\%) (risk difference of $16.0 \%$, 95\% CI: $9.2 \%$ to $22.8 \%$ ). Responses to selected DBC-P24 items are displayed in Table S2, while responses are summarised as mean and standard deviation (SD) in Table 3. Adolescents from SESs had higher scores in many behavioural domains than those from SEUs, including becoming over-excited, being upset or distressed over small changes in routine or environment, and being preoccupied with only one or two particular interests (Table 3). Almost seven percent of participants had psychiatric conditions reported by carers (Table 1).

CHAP booklets were completed for 176 participants. Of these, $65.8 \%$ had significant psychopathology as ascertained by the DBC-P24, and $4.6 \%$ of participants had psychiatric conditions reported by carers. Headache (46.9\%), cough (39.8\%), musculoskeletal symptoms (muscle pain or weakness: $36.1 \%$; joint or back pain: $30.3 \%$ ), constipation $(25.6 \%)$, and sleep problems $(24.1 \%)$ were commonly reported in the preceding year. Obvious dental 
pathology was common among participants (21.7\%). Sleep problems, regurgitation and vomiting, diarrhoea, faecal incontinence, urinary incontinence, and unsteady gait were more common in SESs than SEUs, while shortness of breath was more common in SEUs than SESs (Table 4). Over half (54.4\%) of participants had vision problems reported, $37.9 \%$ had glasses prescribed, and $21.2 \%$ usually wore glasses. In addition, $17.1 \%$ of participants had hearing problems, $4.4 \%$ were prescribed a hearing aid, $3.4 \%$ wore a hearing aid, and $0.6 \%$ used other hearing devices.

Table 3. Behaviour problems of participants in the Ask study who completed baseline questionnaires $(n=592)$.

\begin{tabular}{|c|c|c|c|c|}
\hline Behaviour Problems ${ }^{1}$ & $\begin{array}{l}\text { Total }(n=592) \\
\text { Mean (SD) }\end{array}$ & $\begin{array}{l}\text { Special Education School } \\
\qquad(n=320) \\
\text { Mean (SD) }\end{array}$ & $\begin{array}{l}\text { Special Education } \\
\text { Unit }(n=272) \\
\text { Mean (SD) }\end{array}$ & $\begin{array}{l}\text { Mean Difference } \\
\quad(95 \% \mathrm{CI})\end{array}$ \\
\hline Becomes over-excited & $1.14(0.79)$ & $1.28(0.75)$ & $0.97(0.80)$ & $0.31(0.18$ to 0.44$)$ \\
\hline Stubborn, disobedient, or uncooperative & $0.99(0.73)$ & $1.04(0.74)$ & $0.94(0.72)$ & $0.10(-0.05$ to 0.25$)$ \\
\hline $\begin{array}{l}\text { Upset and distressed over small changes } \\
\text { in routine or environment }\end{array}$ & $1.04(0.82)$ & $1.16(0.80)$ & $0.90(0.82)$ & $0.27(0.13$ to 0.41$)$ \\
\hline Tense, anxious, worried & $0.92(0.74)$ & $0.94(0.77)$ & $0.90(0.70)$ & $0.03(-0.10$ to 0.17$)$ \\
\hline $\begin{array}{l}\text { Preoccupied with only one or two } \\
\text { particular interests }\end{array}$ & $1.09(0.88)$ & $1.23(0.85)$ & $0.93(0.88)$ & $0.30(0.14$ to 0.46$)$ \\
\hline Kicks, hits others & $0.71(0.78)$ & $0.79(0.79)$ & $0.62(0.75)$ & $0.17(0.01$ to 0.32$)$ \\
\hline Wanders aimlessly & $0.43(0.69)$ & $0.51(0.74)$ & $0.33(0.60)$ & $0.18(0.06$ to 0.30$)$ \\
\hline $\begin{array}{c}\text { Refuses to go to school, activity centre, or } \\
\text { workplace }\end{array}$ & $0.38(0.60)$ & $0.33(0.58)$ & $0.42(0.62)$ & $\begin{array}{l}-0.09(-0.20 \text { to } \\
0.02)\end{array}$ \\
\hline $\begin{array}{l}\text { Has nightmares, night terrors, or walks } \\
\text { in sleep }\end{array}$ & $0.39(0.66)$ & $0.42(0.68)$ & $0.36(0.63)$ & $0.06(-0.05$ to 0.16$)$ \\
\hline $\begin{array}{c}\text { Inappropriate sexual activity with } \\
\text { another }\end{array}$ & $0.21(0.53)$ & $0.25(0.57)$ & $0.17(0.47)$ & $0.08(-0.01$ to 0.17$)$ \\
\hline Sees, hears something that is not there & $0.18(0.49)$ & $0.18(0.51)$ & $0.17(0.46)$ & $0.01(-0.07$ to 0.09$)$ \\
\hline
\end{tabular}

${ }^{1}$ Behaviour problems were reported during the past 6 months. Selected items from the DBC2 copyright $\odot 2018$ by Western Psychological Services. Reprinted by T. Le, University of Queensland, by permission of the publisher, WPS. Any additional use permitted in whole or in part for any other purpose without the prior, written authorization of WPS (rights@wpspublish.com).

Table 4. Frequency and percentage of symptoms in the last year and obvious dental pathology from GP examination among participants who completed CHAP booklets $(n=176)$.

\begin{tabular}{|c|c|c|c|c|}
\hline Symptoms & $\begin{array}{c}\text { Total }(n=176) \\
n(\%)\end{array}$ & $\begin{array}{c}\text { Special Education } \\
\text { School }(n=97) \\
n(\%)\end{array}$ & $\begin{array}{c}\text { Special Education } \\
\text { Unit }(n=79) \\
n(\%)\end{array}$ & Risk Difference (95\% CI) \\
\hline \multicolumn{5}{|l|}{ Respiratory system } \\
\hline Cough & $68(39.8 \%)$ & $40(42.6 \%)$ & $28(36.4 \%)$ & $6.2 \%(-12.8 \%$ to $25.2 \%)$ \\
\hline Shortness of breath & $27(16.3 \%)$ & $11(12.0 \%)$ & $16(21.6 \%)$ & $-9.7 \%(-18.5 \%$ to $-0.9 \%) *$ \\
\hline Wheeze & $17(9.9 \%)$ & $9(9.6 \%)$ & $8(10.3 \%)$ & $-0.7 \%(-8.6 \%$ to $7.2 \%)$ \\
\hline Sleep problems & $40(24.1 \%)$ & $29(31.5 \%)$ & $11(14.9 \%)$ & $16.7 \%(4.2 \%$ to $29.1 \%) * *$ \\
\hline \multicolumn{5}{|l|}{ Cardiovascular system } \\
\hline Chest pain & $5(3.0 \%)$ & $4(4.6 \%)$ & $1(1.3 \%)$ & $3.3 \%(-1.6 \%$ to $8.3 \%)$ \\
\hline \multicolumn{5}{|l|}{ Musculoskeletal System } \\
\hline Joint pain/back pain & $47(30.3 \%)$ & $20(24.4 \%)$ & $27(37.0 \%)$ & $-12.6 \%(-26.0 \%$ to $0.8 \%)$ \\
\hline Muscle pain/weakness & $56(36.1 \%)$ & $30(36.1 \%)$ & $26(36.1 \%)$ & $0.0 \%(-16.1 \%$ to $16.1 \%)$ \\
\hline Scoliosis/contractures & $20(12.8 \%)$ & $13(15.7 \%)$ & $7(9.6 \%)$ & $6.1 \%(-4.9 \%$ to $17.0 \%)$ \\
\hline \multicolumn{5}{|l|}{ Gastrointestinal system } \\
\hline Dysphagia & $9(5.2 \%)$ & $7(7.5 \%)$ & $2(2.6 \%)$ & $4.9 \%(-1.9 \%$ to $11.7 \%)$ \\
\hline Regurgitate/vomit & $22(12.7 \%)$ & $19(20.2 \%)$ & $3(3.8 \%)$ & $16.4 \%(5.0 \% \text { to } 27.8 \%)^{* *}$ \\
\hline Diarrhoea & $27(16.1 \%)$ & $23(25.3 \%)$ & $4(5.2 \%)$ & $20.1 \%(6.2 \% \text { to } 34.0 \%)^{* *}$ \\
\hline Constipation & $43(25.6 \%)$ & $27(29.0 \%)$ & $16(21.3 \%)$ & $7.7 \%(-4.8 \%$ to $20.2 \%)$ \\
\hline Faecal incontinence & $25(14.5 \%)$ & $22(23.7 \%)$ & $3(3.8 \%)$ & $19.9 \%(9.9 \%$ to $29.8 \%) * * *$ \\
\hline Abdominal pain & $31(19.8 \%)$ & $21(25.3 \%)$ & $10(13.5 \%)$ & $11.8 \%(-2.4 \%$ to $26.0 \%)$ \\
\hline \multicolumn{5}{|l|}{ Urinary system } \\
\hline Urinary incontinence & $30(17.7 \%)$ & $23(25.3 \%)$ & $7(8.9 \%)$ & $16.4 \%(1.5 \%$ to $31.3 \%) *$ \\
\hline \multicolumn{5}{|l|}{ Nervous system } \\
\hline Headache & $75(46.9 \%)$ & $34(41.0 \%)$ & $41(53.3 \%)$ & $-12.3 \%(-28.0 \%$ to $3.4 \%)$ \\
\hline Unsteady gait & $23(14.3 \%)$ & $17(19.5 \%)$ & $6(8.1 \%)$ & $11.4 \%(1.2 \%$ to $21.7 \%) *$ \\
\hline Limb weakness & $24(15.9 \%)$ & $12(14.8 \%)$ & $12(17.1 \%)$ & $-2.3 \%(-15.0 \%$ to $10.4 \%)$ \\
\hline Paraesthesia & $10(7.2 \%)$ & $2(3.0 \%)$ & $8(11.1 \%)$ & $-8.1 \%(-16.7 \%$ to $0.5 \%)$ \\
\hline
\end{tabular}


Table 4. Cont.

\begin{tabular}{|c|c|c|c|c|}
\hline Symptoms & $\begin{array}{c}\text { Total }(n=176) \\
n(\%)\end{array}$ & $\begin{array}{c}\text { Special Education } \\
\text { School }(n=97) \\
n(\%)\end{array}$ & $\begin{array}{c}\text { Special Education } \\
\text { Unit }(n=79) \\
n(\%)\end{array}$ & Risk Difference (95\% CI) \\
\hline \multicolumn{5}{|l|}{ Skin system } \\
\hline Eczema & $21(12.4 \%)$ & $9(9.7 \%)$ & $12(15.8 \%)$ & $-6.1 \%(-13.5 \%$ to $1.3 \%)$ \\
\hline Other dermatological disease(s) & $25(14.9 \%)$ & $17(18.3 \%)$ & $8(10.7 \%)$ & $7.6 \%(-2.0 \%$ to $17.2 \%)$ \\
\hline Obvious dental pathology & $36(21.7 \%)$ & $24(25.8 \%)$ & $12(16.4 \%)$ & $9.4 \%(-2.1 \%$ to $20.8 \%)$ \\
\hline
\end{tabular}

${ }^{*} p<0.05,{ }^{* *} p<0.01,{ }^{* * *} p<0.001$.

\section{Discussion}

\subsection{Principal Findings}

Adolescents with intellectual disability have significant health needs. The majority of study participants $(65.4 \%)$ had at least one chronic medical or psychiatric condition reported by carers. The carer-reported prevalence of chronic physical medical conditions was also high (64.2\%). Two-thirds of participants had significant psychopathology $(67.2 \%)$ by DBC-P24, and the majority had difficulty in normal life activities. Adolescents from SESs are more likely to have significant behaviour problems and have difficulty in their normal life activities compared with those from SEUs. Vision, hearing, and dental problems are common. A significant portion of participants with intellectual disability experienced symptoms in the year before questionnaire completion.

\subsection{Comparison with Other Studies}

In our study, adolescents with intellectual disability showed significant health issues in terms of general health status, chronic health conditions, dental pathologies, level of functioning, and psychiatric and behaviour problems, consistent with earlier studies $[4,5,10,11,26]$.

The prevalence of significant psychopathology ascertained by the DBC-P24 (67.2\%) was much higher than that of psychiatric conditions reported by carers $(6.6 \%)$, and also higher than the prevalence of mental health disorders among adolescents with intellectual disability reported by carers (about $20 \%$ ) in previous studies [5,11]. Partial explanations include the difficulty of recognising mental health problems in adolescents, official diagnoses not being made, carers not reporting developmental disorders (including ASD and ADHD) as psychiatric conditions, and the fact that carers may attribute adolescents' behaviours and symptoms to their intellectual disability [27]. Failure to recognise mental health problems could lead to failure to meet a young person's health needs.

As expected, we found that adolescents from SESs were more likely to have more difficulty in their normal life activities and significant behaviour problems compared with those from SEUs. These findings are consistent with a Dutch study of children and adolescents with intellectual disability [28].

A significant portion of adolescents with intellectual disability experienced symptoms that are common in adults with intellectual disability and non-disabled adults, such as headache, cough, sleep problems, constipation, joint pain, and back pain [29,30]. However, some symptoms are uncommon in the general population, but prevalent among our participants, including dysphagia and unsteady gait. Our study reported a significant difference in the prevalence of sleep problems between participants from SESs and SEUs, as supported by literature on children and adults with intellectual disability [31,32]. We also found that the prevalence of urinary and faecal incontinence was higher among participants from SESs than participants from SEUs, which was consistent with past studies [33].

\subsection{Recommendations and Implications for Policies and Future Research}

Given the significant health concerns, behavioural problems, and functional impairments, additional resources are needed. These include more training for primary health care providers for the identification and management of behavioural and mental health concerns among young people with intellectual disability, school-based health services 
to complement existing allied health services in both special schools and mainstream schools that adolescents with milder disability attend, and greater support for life skills, self-determination, and personal development to support these students and their families to improve functioning at home and in the community. This is particularly important for adolescents with intellectual disability because of their high needs and inadequate access to appropriate services [7]. Providing primary health care services, such as vaccination, dental checks, and vision and hearing tests on school campuses could reduce access barriers, such as transportation problems, and potentially improve short- and long-term health outcomes in this population [34]. We recommend routine health checks in clinical care for adolescents with intellectual disability [35,36]. The intervention used in the Ask study increased health actions and self-determination in our population [16,17]. Data on the health status of adolescents with intellectual disability are scarce, and more research in this field is needed regarding barriers to health care access, especially during the transition from the paediatric to the adult health care system, as well as in unmet and unrecognised health problems for this population.

Transitions in the lives of people with intellectual and developmental disabilities are disruptive, often to a greater degree than is the case for others. Examples include changing residence and the transition from primary to secondary school. System changes are needed to address these transitions, and no single strategy will suffice. Among our recommendations are greater use of a universal electronic health record system (such as My Health Record in Australia); coordination between sectors, particularly education and health, for transfer of health records; and, in Australia, the use of Chronic Disease Management item numbers by GPs to provide adequate support during these transitions. Programs to reduce stigma against and increase social inclusion and employment opportunities for adolescents with intellectual disability are also needed, as these programs can reduce mental and physical problems for this population [37]. Societal and environmental interventions beyond health and education systems are essential to the health of adolescents with intellectual disability. The structures and organisations that will support the needed changes in Australia are diverse, and for different individuals may include sporting organisations, organised religion, various levels of government, and others.

\subsection{Strengths and Limitations}

Our study has some limitations. Carers were asked to report symptoms over a 12 -month period and may not recall some symptoms during this period. We did not use standardised assessment tools to assess symptoms. Our data are from 2007. An increasing proportion of children with intellectual disabilities live to adolescence as health care services improve. Therefore, our findings may underestimate health service demands. Some participants' intellectual disabilities were diagnosed by guidance officers rather than health professionals and could not be verified by the researchers.

However, our study is the first to describe the prevalence of symptoms experienced by adolescents with intellectual disability, their behaviour problems, and restrictions in everyday life activities in such detail. We report the prevalence of wearing glasses, wearing a hearing aid, and dental problems, and these have not been reported before. Data on the health status of Australian adolescents with intellectual disability are lacking. Our results fill a significant knowledge gap. The study sample is relatively large. In the field of intellectual disability research, this study is unique in that it is based on a representative community sample. Although these data were collected as part of a randomised trial, we combined all participants in analyses as baseline questionnaires were completed before intervention initiation. Symptoms were extracted from the CHAP booklet; however, rate of disease diagnosis was not influenced by the intervention package [17], and consequently our results are unlikely to be affected by the intervention.

Our results are likely to have good external validity, as drop-out was not associated with participant characteristics [38], and the mean (SD) age and gender distribution of participants who had baseline questionnaires completed were comparable to all eligible 
high school students with intellectual disability in South-East Queensland [17]. Although the data were collected in 2007, the findings remain relevant, as changes in health and healthcare for Australian adolescents with intellectual disability have not been great, despite the introduction of the National Disability Insurance Scheme. While SEUs in mainstream schools no longer exist in Queensland, our results remain applicable because the criteria for a disabled student to attend a normal or special school remain unchanged.

\section{Conclusions}

Findings from this study show that adolescents with intellectual disability, especially those from special schools, have significant health needs. More should be done to improve the health status of this population, including greater support for personal development, particularly life skills and self-determination, more resources (health care and promotion), and health research. We also suggest the routine use of comprehensive health checks and a universal electronic health record, as well as coordination between sectors to facilitate the difficult transition process for this population. This study provides crucial data to assist policy makers, healthcare professionals, and teachers in developing more effective and targeted health promotion and disease prevention programs for this population.

Supplementary Materials: The following are available online at https:/ /www.mdpi.com/article/10 .3390/disabilities1040026/s1, Table S1: Demographic, social, and clinical characteristics of participants in the Ask study who completed CHAP health check booklets $(n=176)$, Table S2: Responses for selected behaviour problems for participants who completed baseline questionnaires $(n=592)$.

Author Contributions: Conceptualization, T.T.A.L.; D.H.; R.S.W.; S.D.; N.L. and L.M.; methodology, T.T.A.L.; D.H.; R.S.W.; S.D.; N.L.; and L.M.; formal analysis, T.T.A.L.; investigation, N.L. and L.M.; data curation, R.S.W. and L.M.; writing—original draft preparation, T.T.A.L.; writing—review and editing, D.H.; R.S.W.; S.D.; N.L.; and L.M.; visualization, T.T.A.L.; supervision, D.H.; R.S.W.; S.D.; N.L.; and L.M.; project administration, T.T.A.L.; D.H. and L.M.; funding acquisition, N.L. All authors have read and agreed to the published version of the manuscript.

Funding: The original study—the Ask study—was funded by the National Health and Medical Research Council (NHMRC), grant number 401647.

Institutional Review Board Statement: The study was conducted according to the guidelines of the Declaration of Helsinki, and approved by the Queensland Government Department of Education and the Arts (File No: 550/27/424) and the University of Queensland Behavioural and Social Sciences Ethical Review Committee (Clearance No: 2004000081).

Informed Consent Statement: Informed consent was obtained from all principals or heads of schools, teachers, carers and nominated GPs.

Data Availability Statement: The data are not publicly available due to privacy restriction. To discuss accessing the Ask Study data please contact the authors at qcidd@uq.edu.au.

Acknowledgments: We would like to thank Charmaine Driver, the Principal of Darling Point Special School for her suggestions during the development of the manuscript.

Conflicts of Interest: UniQuest, a University of Queensland corporate branch, licenses the usage of the CHAP. One-third of the profit is paid to Nicholas Lennox (the fourth author). Nicholas Lennox, Tran Tuan Anh Le, David Harley, Lyn McPherson and Robert Ware have or used to have affiliations with the Queensland Centre for Intellectual and Developmental Disability (QCIDD), the University of Queensland, which receives another one-third of the commission to support the Centre's research. Simon Denny has no competing interests. The funders (NHMRC and UniQuest) had no role in the design of the study; in the collection, analyses, or interpretation of data; in the writing of the manuscript, or in the decision to publish the results. 


\section{References}

1. Maulik, P.K.; Mascarenhas, M.N.; Mathers, C.D.; Dua, T.; Saxena, S. Prevalence of intellectual disability: A meta-analysis of population-based studies. Res. Dev. Disabil. 2011, 32, 419-436. [CrossRef]

2. Truesdale, M.; Brown, M. People with Learning Disabilities in Scotland: 2017 Health Needs Assessment Update Report; NHS Health Scotland: Glasgow, Scotland, 2017; p. 6.

3. Weise, J.C.; Srasuebkul, P.; Trollor, J.N. Potentially preventable hospitalisations of people with intellectual disability in New South Wales. Med. J. Aust. 2021, 215, 31-36. [CrossRef] [PubMed]

4. Oeseburg, B.; Jansen, D.E.M.C.; Dijkstra, G.J.; Groothoff, J.W.; Reijneveld, S.A. Prevalence of chronic diseases in adolescents with intellectual disability. Res. Dev. Disabil. 2010, 31, 698-704. [CrossRef] [PubMed]

5. Young-Southward, G.; Rydzewska, E.; Philo, C.; Cooper, S.-A. Physical and mental health of young people with and without intellectual disabilities: Cross-sectional analysis of a whole country population. J. Intellect. Disabil. Res. 2017, 61, 984-993. [CrossRef] [PubMed]

6. Hughes-McCormack, L.A.; Rydzewska, E.; Henderson, A.; MacIntyre, C.; Rintoul, J.; Cooper, S.-A. Prevalence of mental health conditions and relationship with general health in a whole-country population of people with intellectual disabilities compared with the general population. BJPsych Open 2017, 3, 243-248. [CrossRef] [PubMed]

7. Franklin, M.S.; Beyer, L.N.; Brotkin, S.M.; Maslow, G.R.; Pollock, M.D.; Docherty, S.L. Health Care Transition for Adolescent and Young Adults with Intellectual Disability: Views from the Parents. J. Pediatr. Nurs. 2019, 47, 148-158. [CrossRef] [PubMed]

8. Heron, L.M.; Agarwal, R.; Greenup, J.; Maddux, M.; Attong, N.; Burke, S.L. Disparities in healthcare transition support received by adolescents with special healthcare needs. J. Appl. Res. Intellect. Disabil. 2020, 33, 180-192. [CrossRef]

9. Westwood, W. Children with Mental Retardation/Intellectual Disability: The Function of Adaptive Behavior and Parental Stress Across Childhood. Doctoral Dissertation, Duquesne University, Pittsburgh PA, USA, 2010.

10. Emerson, E.; Kiernan, C.; Alborz, A.; Reeves, D.; Mason, H.; Swarbrick, R.; Mason, L.; Hatton, C. The prevalence of challenging behaviors: A total population study. Res. Dev. Disabil. 2001, 22, 77-93. [CrossRef]

11. Bhaumik, S.; Watson, J.; Barrett, M.; Raju, B.; Burton, T.; Forte, J. Transition for Teenagers With Intellectual Disability: Carers' Perspectives. J. Policy Pract. Intellect. Disabil. 2011, 8, 53-61. [CrossRef]

12. Nicholls, G.; Hastings, R.P.; Grindle, C. Prevalence and correlates of challenging behaviour in children and young people in a special school setting. Eur. J. Spec. Needs Educ. 2020, 35, 40-54. [CrossRef]

13. Song, M.; Ware, R.S.; Doan, T.N.; McPherson, L.; Trollor, J.N.; Harley, D. Appropriateness of psychotropic medication use in a cohort of adolescents with intellectual disability in Queensland, Australia. BJPsych Open 2020, 6, e142. [CrossRef]

14. Doan, T.; Ware, R.; McPherson, L.; van Dooren, K.; Bain, C.; Carrington, S.; Einfeld, S.; Tonge, B.; Lennox, N. Psychotropic medication use in adolescents with intellectual disability living in the community. Pharmacoepidemiol. Drug Saf. 2014, 23, 69-76. [CrossRef]

15. Lennox, N.; Ware, R.; Carrington, S.; O'Callaghan, M.; Williams, G.; McPherson, L.; Bain, C. Ask: A health advocacy program for adolescents with an intellectual disability: A cluster randomised controlled trial. BMC Public Health 2012, 12, 750. [CrossRef]

16. McPherson, L.; Ware, R.S.; Carrington, S.; Lennox, N. Enhancing Self-Determination in Health: Results of an RCT of the Ask Project, a School-Based Intervention for Adolescents with Intellectual Disability. J. Appl. Res. Intellect. Disabil. 2017, 30, 360-370. [CrossRef] [PubMed]

17. Lennox, N.; McPherson, L.; Bain, C.; O'Callaghan, M.; Carrington, S.; Ware, R.S. A health advocacy intervention for adolescents with intellectual disability: A cluster randomized controlled trial. Dev. Med. Child. Neurol. 2016, 58, 1265-1272. [CrossRef] [PubMed]

18. Australian Bureau of Statistics. Census of Population and Housing: Socio-Economic Indexes for Areas (SEIFA); ABS: Canberra, Australia, 2008.

19. Mahoney, F.I.; Barthel, D.W. Functional Evaluation: The Barthel Index. Md. State. Med. J. 1965, 14, 61-65.

20. Taffe, J.R.; Gray, K.M.; Einfeld, S.L.; Dekker, M.C.; Koot, H.M.; Emerson, E.; Koskentausta, T.; Tonge, B.J. Short Form of the Developmental Behaviour Checklist. Am. J. Ment. Retard. 2007, 112, 31-39. [CrossRef]

21. Einfeld, S.L.; Tonge, B.J. The Developmental Behavior Checklist: The development and validation of an instrument to assess behavioral and emotional disturbance in children and adolescents with mental retardation. J. Autism Dev. Disord. 1995, 25, 81-104. [CrossRef] [PubMed]

22. Lennox, N.; Bain, C.; Rey-Conde, T.; Purdie, D.; Bush, R.; Pandeya, N. Effects of a comprehensive health assessment programme for Australian adults with intellectual disability: A cluster randomized trial. Int. J. Epidemiol. 2007, 36, 139-146. [CrossRef]

23. Lennox, N. A Randomised Cluster Study of an Intervention Aimed at Improving the Health Outcomes of Adults with an Intellectual Disability. Doctoral Dissertation, University of Queensland, Queensland, Australia, 2007.

24. Lennox, N.G.; Rey-Conde, T.F.; Faint, S.L. A Pilot of Interventions to Improve Health Care in Adolescents with Intellectual Disability. J. Appl. Res. Intellect. Disabil. 2008, 21, 484-489. [CrossRef]

25. Bakker-van Gijssel, E.J.; Lucassen, P.L.B.J.; Olde Hartman, T.C.; van Son, L.; Assendelft, W.J.J.; van Schrojenstein Lantman-de Valk, H.M.J. Health assessment instruments for people with intellectual disabilities-A systematic review. Res. Dev. Disabil. 2017, 64, 12-24. [CrossRef]

26. Ward, L.M.; Cooper, S.A.; Hughes-McCormack, L.; Macpherson, L.; Kinnear, D. Oral health of adults with intellectual disabilities: A systematic review. J. Intellect. Disabil. Res. 2019, 63, 1359-1378. [CrossRef] 
27. Faust, H.; Scior, K. Mental Health Problems in Young People with Intellectual Disabilities: The Impact on Parents. J. Appl. Res. Intellect. Disabil. 2008, 21, 414-424. [CrossRef]

28. De Bildt, A.; Sytema, S.; Kraijer, D.; Sparrow, S.; Minderaa, R. Adaptive functioning and behaviour problems in relation to level of education in children and adolescents with intellectual disability. J. Intellect. Disabil. Res. 2005, 49, 672-681. [CrossRef] [PubMed]

29. Elnegaard, S.; Andersen, R.S.; Pedersen, A.F.; Larsen, P.V.; Søndergaard, J.; Rasmussen, S.; Balasubramaniam, K.; Svendsen, R.P.; Vedsted, P.; Jarbøl, D.E. Self-reported symptoms and healthcare seeking in the general population-Exploring “The Symptom Iceberg". BMC Public Health 2015, 15, 685. [CrossRef] [PubMed]

30. Osugo, M.; Morrison, J.; Allan, L.; Kinnear, D.; Cooper, S.A. Prevalence, types and associations of medically unexplained symptoms and signs. A cross-sectional study of 1023 adults with intellectual disabilities. J. Intellect. Disabil. Res. 2017, 61, 637-642. [CrossRef] [PubMed]

31. Didden, R.; Korzilius, H.; Aperlo, B.V.; Overloop, C.V.; Vries, M.D. Sleep problems and daytime problem behaviours in children with intellectual disability. J. Intellect. Disabil. Res. 2002, 46, 537-547. [CrossRef]

32. Quine, L. Sleep problems in primary school children: Comparison between mainstream and special school children. Child. Care Health Dev. 2001, 27, 201-221. [CrossRef]

33. von Wendt, L.; Similä, S.; Niskanen, P.; Järvelin, M.-R. Development of bowel and bladder control in the mentally retarded. Dev. Med. Child. Neurol. 1990, 32, 515-518. [CrossRef]

34. Arenson, M.; Hudson, P.J.; Lee, N.; Lai, B. The Evidence on School-Based Health Centers: A Review. Glob. Pediatr. Health 2019, 6, 2333794X19828745. [CrossRef]

35. Robertson, J.; Hatton, C.; Emerson, E.; Baines, S. The impact of health checks for people with intellectual disabilities: An updated systematic review of evidence. Res. Dev. Disabil. 2014, 35, 2450-2462. [CrossRef]

36. Byrne, J.H.; Lennox, N.G.; Ware, R.S. Systematic review and meta-analysis of primary healthcare interventions on health actions in people with intellectual disability. J. Intellect. Dev. Disabil. 2016, 41, 66-74. [CrossRef]

37. Emerson, E.; Baines, S.; Allerton, L.; Welch, V. Health Inequalities \& People with Learning Disabilities in the UK: 2012; Improving Health and Lives: Learning Disabilities Observatory: Durham, UK, 2012; pp. 15-18.

38. Ware, R.S.; McPherson, L.; Lennox, N.G. Drop-out during a randomized trial with adolescents with intellectual disability was associated with participant burden, while drop-out at study exit was associated with carer and household characteristics. Res. Dev. Disabil. 2017, 71, 53-60. [CrossRef] [PubMed] 